\title{
Attachment Play Related to Piaget's Conservation Task with Parent
}

\author{
Nobuki Watanabe ${ }^{1}$ \\ ${ }^{1}$ School of Education, Kwansei Gakuin University, Hyogo, Japan \\ Correspondence: Nobuki Watanabe, School of Education, Kwansei Gakuin University, Hyogo, Japan. E-mail: \\ nobuki@kwansei.ac.jp
}

Received: February 25, 2019

Accepted: March 24, 2019

Online Published: March 25, 2019

doi:10.5539/ijps.v11n2p24

URL: https://doi.org/10.5539/ijps.v11n2p24

\begin{abstract}
Piaget's conservation concept still influences many disciplines such as pedagogy and psychology. It is said that this idea is difficult for children to acquire before they are 6 years old if Piaget's task methods are adhered to. This study aims to verify whether the acquisition of the conservation concept (substance, weight, and volume) can be accelerated through an intentional environmental change (the setting of play related to conservation accompanied by the development of affection with parent). To this end, a single case study was conducted on a 3 -year-old child. Specifically, monthly retention tasks (and related content) were executed in the form of a quiz game. The results of the experiment suggested that the conservation concept may be obtained by 3 -year-old children. Hence, it may be asserted that play related to conservation accompanied by the formation of attachment with a parent influences the early acquisition of the conservation concepts of substance, weight, and volume.
\end{abstract}

Keywords: attachment play, conservation concept (substance, weight, volume), Piaget's conservation task

\section{Introduction}

The conservation concept is one of the logical ideas studied by Jean Piaget and it informs the understanding of the principle of invariance (Goswami, 1998). Research on this concept is conducted through the use of number, length, liquid, substance, weight, volume, etc. The conservation concepts of substance, weight, and volume, are considered difficult to acquire and the measurement their stages of acquisition is assessed through Piaget's conservation tasks (Piaget \& Inhelder, 1974) as described below:

(1) Substance: A child is shown two clay balls (A1, A2) of the same size and weight, and confirms that they have the same substance. A2 is lengthened or flattened, and the child is asked whether its substance is equal to that of A1 (Figures 1 and 2). Children come to recognize that the two shapes are equal in size and weight at the age of $8-10$.

(2) Weight: A child is shown two clay balls (A1, A2) of the same size and weight, and confirms that the balls are of the same weight. A2 is lengthened or flattened, and the child is asked whether it is equal in weight to A1 (Figures 2 and 3). Children come to recognize that the two objects are equal at the age of 10-12.

(3) Volume: A child is shown two clay balls (A1, A2) of the same size and weight. Thereafter, A2 is submerged in water, and A1 is lengthened or flattened and submerged in water. The child is asked whether A2 is equal in volume to A1 (Figures 4 and 5). Children come to recognize that the two shapes are equal in volume at the age of $11-12$ or older. 


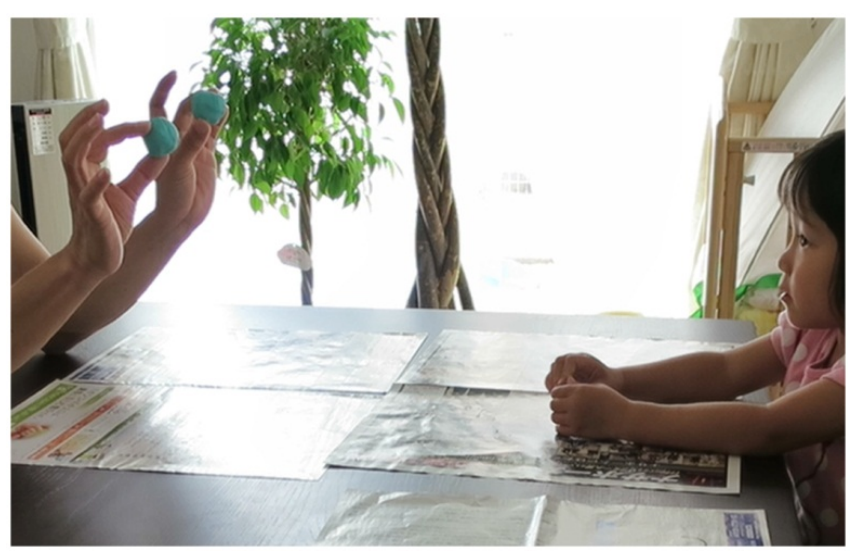

Figure 1. Substance task

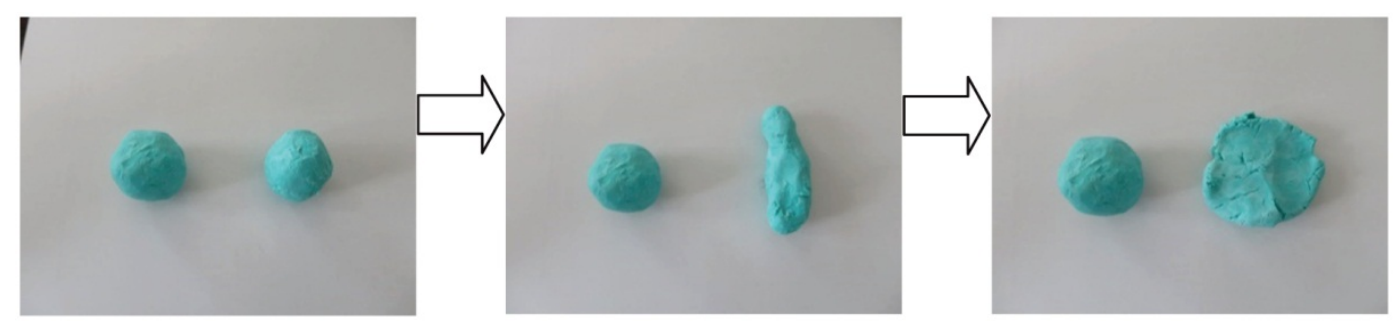

Figure 2. Substance and weight task

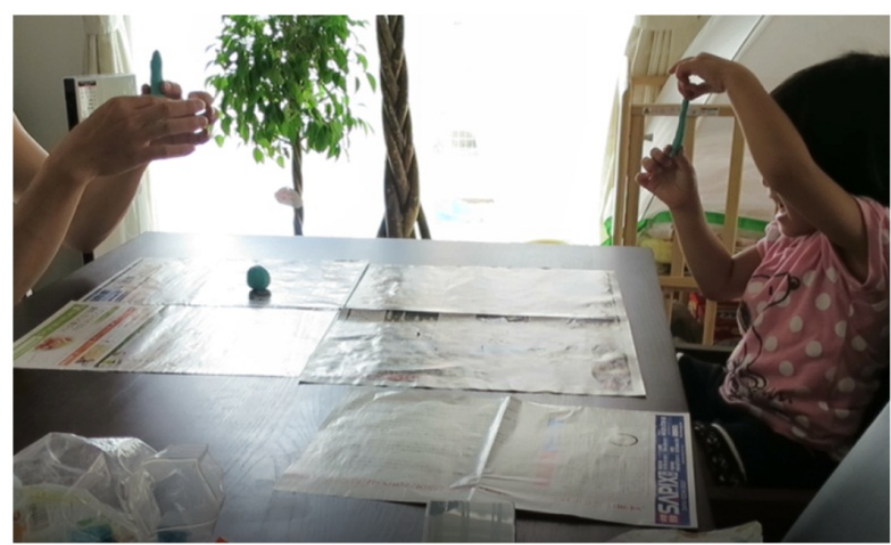

Figure 3. Weight task

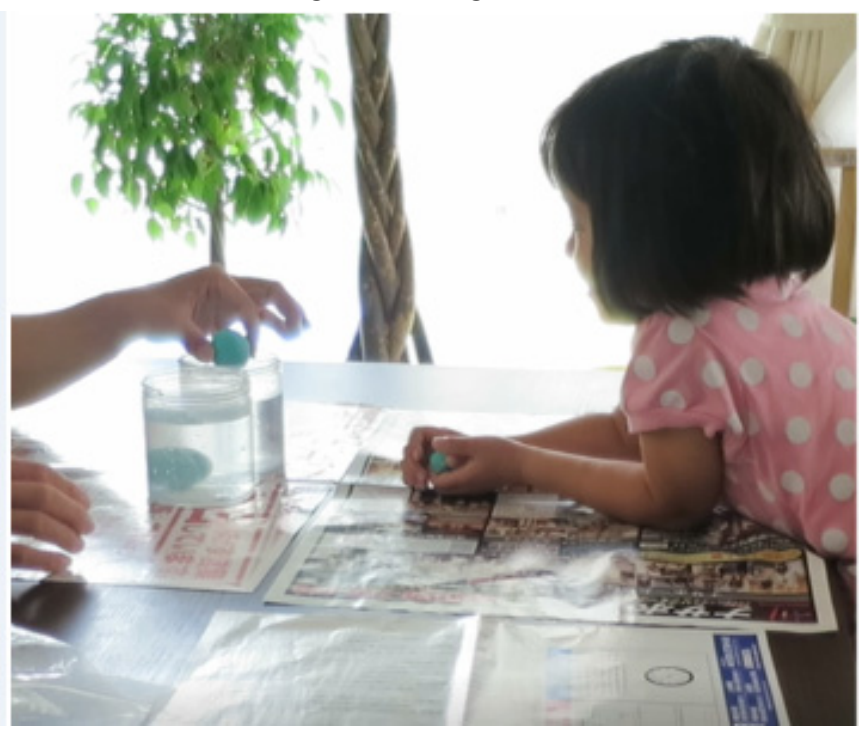

Figure 4. Volume task 


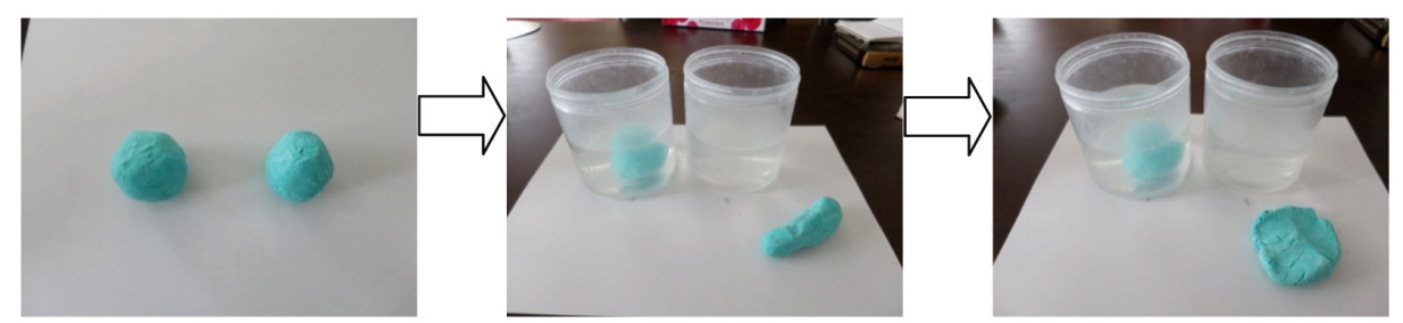

Figure 5. Volume task

Although Piaget posits that the ages at which each stage of conservation is dependent on age-related cognitive development, others have observed younger ranges. For example, cognitive age of substance occurs at 6 to 7 years old, the notion of weight is acquired when a child is 9 years old, and the cognition of volume happens at 11 years of age or older (Hetherington \& Parke, 2003). It has also been indicated that the acquisition phases may be accelerated through replication study (Watanabe, 2017a).

Early acquisition may be explained through the acceleration phenomenon of cognitive development exemplified by effects like the Flynn effect, which has evidenced that the average IQ has continued to rise dramatically over the 100 years that have elapsed since the beginning of the 20th century (Flynn, 2012). The Flynn effect is the term used to describe a general increase in IQ scores; however, this effect is thought to be due to social change, most notably due to environmental factors (Flynn, 2013). Moreover, recent studies have also indicated the possibility of genetic-environment interaction (Heckman, 2013) and of the cross-fertilization of non-cognitive and cognitive skills (OECD, 2015). Hence, due to intentional environmental change, further development acceleration may be expected. Thus, this form of intentional environmental change may have the effect of accelerating developmental cognition beyond that proposed by Piaget. Today, it is said that if, for instance, Piaget's methods of application of his conservation tasks are maintained, it would be difficult for a child under the age of 6 years to acquire conservation concepts. (Goswami, 1998; Siegler, 1986)

Guided play is a form of intentional change in the environment that is thought to affect cognitive development in early childhood (Weisberg, Hirsh-Pasek, Golinkoff, Kittredge \& Klahr, 2016). The utilization of guided play may be considered for Piaget's conservation tasks if it encompasses the following features: first, high attachment play that is more nurturing, very involved, highly responsive, and rather demanding (Eliot, 1999) is now deemed important for the enhancement of non-cognitive skills and the role of parents is pivotal in this context (OECD, 2015); second, the setting or environment in which the guided play related to Piaget's conservation task (quiz game) occurs is also crucial to the further advancement of a child's cognitive skills.

This study aims to verify whether the acquisition of the conservation concepts of substance, weight, and volume can be accelerated through an intentional change in the setting of the play related to conservation accompanied by the formation of affection with a parent.

\section{Method}

\subsection{Research Design}

A single case study method was adopted. This method is considered suitable for drawing conclusions regarding new hypotheses (Barlow, Nock, \& Hersen, 2009; Yin, 2018). Survey tasks and related content were executed as a quiz game with the parents of the child in this intervention based investigation. For example, the child is shown two clay balls (A1, A2) of the same size and weight, and it was confirmed by the child that the two balls had the same substance as an answer to the question, "Which is bigger?" A2 was subsequently lengthened or flattened and the child was again asked whether its substance was equal to that of A1 through the question, "Which is bigger?" This task was executed every month. The treatment variable (main variable) comprised the survey (play) relating to Piaget's task. The information extraction procedure was obviously difficult; hence, the AB design was adopted.

\subsection{Target}

A three-year-old female child who was engaged in the mathematics quiz from the age of 3 years (36 months). Since the age of 3 years and 2 months ( 38 months), she started to play the Piaget's task of number, length, and liquid, and since the age of 3 years and 7 months ( 43 months), she was involved with Piaget's task of substance, weight, and volume.

\subsection{Characteristics of the Subject Child}

She had no special arithmetic knowledge. 


\subsection{Stages by Age in Months}

Any day in the 1-month period from day zero of turning three until the day before turning 3 years 1 month old (37 months) was considered to be 3 years 0 months (36 months). The timing of the study was arbitrary (Watanabe, 2016).

\subsection{Guided Play (Attachment Play)}

The guided play included the development of attachment (more nurturing, very involved, highly responsive, and rather demanding) with her parent at home (the author is the parent (her father), a father, in question). Around 50-100 quiz (mathematics quiz) items were investigated, and the contents of the questions included mathematics together with Piaget's conservation task. During the early stages of play, the child could answer about 50 items of the quiz, and the number of quiz items (questions) gradually increased with the increase in the child's age. In this context, the content of the queried item was not important; rather, it was vital for the child to accept Piaget's task not as special but everyday play just like the other quiz type games are naturally played in daily conversations with children. Sample questions included: What is the name of this shape? Can you count the numbers? Which is large? Which is big? Which is long? Can you draw a square? Can you weigh this? What time is it? What is this number? What is a similar shape? etc. Details of the listed items can be found in Watanabe's $(2016,2019)$ articles. The child responded to each question item in a game of quiz about once a month. For example, a parent would quiz "Which is big?" The child was free to offer any answer in any manner. In the meantime, playing with things, making her own questions, eating candy on answering was all part of the game. When the child wanted to play a quiz, the parent responded immediately. To play the game of quiz effectively, the parent was required to actively make time to play with the child as much as possible. It was necessary for the parent to not merely investigate, but to also maintain a trusting relationship regarding engaging in play with the child. It was important for a parent to respond as much as possible and as soon as possible to the child's proposal to play. In addition, when the child answered questions, the parent praised her for the response. Regardless of whether the answer was correct or not, I praised them to answer. It was important for children to think freely in this play, so we did not teach them any correct answers. In this way, the parental role was more nurturing, very involved, highly responsive, and rather demanding.

\subsection{Reliability Verification}

As an aspect of everyday play pertaining to Piaget's conservation task, the child was not questioned in principle about the reason why the 2 objects were the same or different because the child did not have enough linguistic ability to express the reasons for her answer. Attempts were made to make the questioning sessions more enjoyable for the child and the interventions continued monthly until the child reached 4 years 0 months (48 months, after which they continued until the child was 6 years old). To clarify, the survey of Piaget's conservation task of number, length, and liquid began when the child was aged 38 months, and substance, weight, and volume began when the child was aged 43 months after acquiring the conservation concept of number, length, and liquid. Piaget's conservation task has been detailed in the introductory section above.

\section{Results}

Table 1 demonstrate the results of the study (The table also shows the results of conservation of number, length, and liquid for reference). Zero indicates an incorrect response and 1 signifies a correct response, and hyphens indicate that tasks are not implemented. Normally, the establishment of an original baseline is achieved before the intervention. However, in this study, the task itself formed the intervention. The child was 43 months old when the substance, weight, and volume task was performed for the first time. At this juncture, the accurate answers were not offered. Furthermore, the child recognized the conservation concept of number, length, and liquid volume at 42 or 43 months (Watanabe, 2017b). Therefore, the baseline can be set to 0 before 43 months. Of course, even if this hypothesis is incorrect, since there is a stage where a conversation cannot be established (for example, a 0 -year-old child), the baseline can be set at 0 regardless. Thus, it is significant that a stable result of 1 was obtained over 5 consecutive periods. Therefore, if the child obtained the conservation concept at 44 months, she may be regarded as having acquired it by 48 months ( 5 consecutive results of 1$)$. 
Table 1. Results of Piaget's conservation task

\begin{tabular}{ccccccc}
\hline $\begin{array}{c}\text { Type } \\
\text { Age (Month) }\end{array}$ & Substance & Weight & Volume & Number & Length & Liquid \\
\hline 38 & - & - & - & 0 & 0 & 0 \\
39 & - & - & - & 0 & 0 & 0 \\
40 & - & - & - & 0 & 0 & 0 \\
41 & - & - & - & 0 & 0 & 0 \\
42 & - & - & - & 0 & 1 & 0 \\
43 & 0 & 0 & 0 & 1 & 1 & 1 \\
44 & 1 & 1 & 1 & 1 & 1 & 1 \\
45 & 1 & 1 & 1 & 1 & 1 & 1 \\
46 & 1 & 1 & 1 & 1 & 1 & 1 \\
47 & 1 & 1 & 1 & 1 & 1 & 1 \\
48 & 1 & 1 & 1 & 1 & 1 & 1 \\
\hline
\end{tabular}

She responded correctly when she was 44 months old and continued to answer correctly until 48 months. Thus, it is suggested that the conservation concept can be obtained by a 3-year-old child and that play related to conservation accompanied by the formation of parental attachment influences the early acquisition of the conservation concepts of substance, weight, and volume.

\section{Discussion}

It has been elucidated that parents exert an impact on the development of children's non-cognitive skills. Verny and Weintraub (2002, p. 57) assert: "Still, it bears repeating: findings in the peer-reviewed literature over the course of decades establish, beyond any doubt, that parents have overwhelming influence on the mental and physical attributes of the children they raise." The National Research Council and Institute of Medicine claims (2000, p. 389, p. 264) that "Parents and other regular caregivers in children's lives are 'active ingredients' of environmental influence during the early childhood period" and that "Relationships are among the most significant influences on healthy growth and psychological well-being." Moreover, the Organisation for Economic Co-operation and Development (OECD) states (2015, p. 82) "The empirical literature also suggests that supportive and warm families that provide stimulating activities enhance children's cognitive, social and emotional skills (Baxter \& Smart, 2011; Cabrera, Fitzgerald, Bradley \& Roggman, 2007; Cunha, Heckman \& Schennach, 2012)".

OECD (2015, p. 132) also suggests that "Parental engagement and attachment have considerable impact on children's early social and emotional development. These are important features that recur most often among successful interventions." Hence, attachment is considered to be particularly important. Attachment is a concept that was established by John Bowlby and developed by Mary Dinsmore Salter Ainsworth (Bowlby, 1969; Bowlby, 1979; Bowlby, 1988). There are many indications that this attachment is more important for nurturing non-cognitive skills. According to Hirsh-Pasek, Golinkoff \& Ever, (2003, p. 189), "Further research has also made clear that the nature of early attachment relationships can have a significant impact on children's emotional and academic adjustment." As Fonagy (2001, p. 25) has indicated, "Maternal caregiving makes a clear contribution to attachment security." Thus, nursing is important for children to acquire attachment security which is maintained if a child continues to stay in a loving and supportive environment (Lamb, Thompson, Gardner \& Charnov, 1985). In other words, the early stages of development of infants and young children alone are insufficient for the institution of attachment. Therefore, the parental aspects of being "more nurturing, very involved with their children, highly responsive to their needs, and rather demanding" are crucial to effective child rearing (Eliot, 1999, p. 451).

Previous studies have suggested that this development of non-cognitive skills is related to the cognitive development of a child and the $\operatorname{OECD}(2015$, p. 132) also asserts that cognitive and social and emotional skills cross-fertilize.

Incidentally, the result of the measurement obtained from the Attachment Q-test of the target child at age 5 was "attachment security." The outcome confirms that play with parents related to Piaget's Conservation Task has the 
effect of attachment formation.

It is difficult to easily apprehend the factors affecting pertaining to attachment that influence the improvement of the non-cognitive skills of a child. Currently, the occurrence of epigenetics is regarded a scientific basis for the effects of attachment. Already, Meaney et al.'s experiments with mice have evidenced that epigenetics occurs due to parenting (Weaver et al., 2004). Moore et al. have explained that in research with human subjects, "we did find evidence overall that variation in tactile contact during early postnatal life associated with DNAm signatures in children" (Moore et al., 2017, p. 1534). It is also being suggested that DNA changes may be observed in response to the childhood environment (McDade et al., 2017). In any case, the current scholarly wisdom holds that the "gene-environment interaction" influences the development of a child (Heckman, 2013; Rutter, 2006; Asbury \& Plomin, 2014; Spector, 2012).

Next, the influence of the father must also be discussed for the purposes of this study as the father was the focal point of the childcare. It has been suggested that the father exerts a positive influence on child rearing. Studies have shown that fathers tend to be more involved with children, that children stabilize emotionally and that the cognitive skills and language abilities are of children are higher when fathers are engaged in child rearing activities (Cabrera et al., 2007). The spirit of challenge and adventure has been found to increase in children when their fathers relate to them (Daniel, 2004). Children who spend a lot of time with their fathers have also been observed to present high IQ at the age of 11 and an elevated social status at the age of 42 (Nettle, 2008). These arguments evince that if the mother's affection is taken for granted, it is conceivable that the father's parenting practices affect a child's cognitive development.

Finally, the importance of play must be underlined. There are numerous indications that play is essential in early childhood (Singer, Golinkoff \& Hirsh-Pasek, 2006; Gray, 2013; Ministry of Education, Culture, Sports, Science, and Technology, 2017). In addition, research suggests that a child's cognitive skills are raised if parents join the play (Hirsh-Pasek et al., 2003).

Regarding Piaget's syllogistic task, Dias \& Harris (1988) have clarified that "it is the make-believe context of play rather than the visible presence of toys during play that facilitates children's reasoning when the premises of the problems run counter to their experience." Hence, the task is not formal and attachment relationships are potentially quite important to its performance.

The definition of play is difficult. The explanation tendered by traditional scholarship may be summarized by the following points: (1) Play is pleasurable and enjoyable. Even when it is not actually accompanied by signs of mirth, it is still positively valued by the player. (2) Play has no extrinsic goals; its motivations are intrinsic and serve no other objectives. In fact, it is more an enjoyment of means than an effort devoted to some particular end. In utilitarian terms, it is inherently unproductive. (3) Play is spontaneous and voluntary. It is not obligatory but is freely chosen by the player. (4) Play involves some active engagement on the part of the player. (5) Play has certain systematic relations to what is not play. (Garvey, 1977, p. 4-5). Recent findings evince that: (1)Play is self-chosen and self-directed; (2) it is an activity in which means are more valued than ends; (3) the structures or rules of play emanate from the minds of the players and are not dictated by physical necessity; (4) play is imaginative, non-literal, and mentally removed in some way from "real" or "serious" life; and (5) play involves an active, alert, but non-stressful frame of mind (Gray, 2013, p. 140). In short, play must be voluntary, active, and fun at the very least.

Given the above elucidation, the guided play related to Piaget's task that was instituted in this study combined with attachment to parents may be said to contribute to the development of a child's non-cognitive skills. It has earlier been shown that the fostering of non-cognitive skills results in the development of cognitive skills. Therefore, it is concluded that these factors are causal for the early acquisition of the conservation concept. The study reconsidered conventional theories of psychology and pedagogy from a novel perspective. The findings revealed that future education and child care of children are interrelated, as it has been pointed out; however, by combining them, this study shows that further possibilities of a child's overall development can be drawn out. Thus, this study demonstrates the flexibility of child's growth against the conventional view in the fields of psychology and pedagogy; I believe that my study would lead future research in these fields towards a new direction in relation to several aspects of child education and care.

Since this study was conducted through a single case method, it would be necessary for future research initiatives to generalize the outcomes by conducting the described investigation with many more children.

\section{Acknowledgments}

This work was supported by JSPS KAKENHI Grant Number 16K01043. 


\section{References}

Asbury, K., \& Plomin, R. (2014). G is for Genes: The impact of genetics on education and achievement. London: Wiley-Blackwell.

Barlow, D. H., Nock, M. K., \& Hersen, M. (2009). Single case experimental designs: Strategies for studying behavior change (3rd ed.). Boston, MA: Allyn and Bacon.

Bowlby, J. (1969). Attachment and Loss (Vol. 1). London, UK; The Hogarth Press.

Bowlby, J. (1979). The Making and Breaking of Affectional Bonds. London: Tavistock Publications.

Bowlby, J. (1988). A secure base Parent child attachment and healthy human development. New York; Basic Books.

Cabrera, N., Fitzgerald, H., Bradley, R., \& Roggman, L. (2007). Modeling the dynamics of paternal influences on children over the life course. Applied Developmental Science, 11(4), 185-190. https://doi.org/10.1080/10888690701762027

Daniel, P. (2004). Theorizing the father-child relationship: mechanisms and developmental outcomes. Human Development, 47(4), 193-219. https://doi.org/10.1159/000078723

Dias, M., \& Harris, P. L. (1988). The effect of make-believe play on deductive reasoning. British Journal of Developmental Psychology, 6(3), 207-221. https://doi.org/10.1111/j.2044-835X.1988.tb01095.x

Eliot, L. (1999). What's going on in there? How the brain and mind develop in the first five years. New York: Bantam Books.

Flynn, J. (2012). Are we getting smarter? Rising IQ in the 21st century. New York: Cambridge University Press. https://doi.org/10.1017/CBO9781139235679

Flynn, J. (2013). Intelligence and human progress: The story of what was hidden in our genes. London: Elsevier.

Fonagy, P. (2001). Attachment theory and psychoanalysis. New York: Other Press

Goswami, U. (1998). Cognition in Children. UK: Psychology Press, Taylor \& Francis

Garvey, C. (1977). Play. Cambridge, MA; Harvard University Press.

Gray, P. (2013). Free to Learn: Why unleashing the instinct to play will make our children happier, more self-reliant, and better students for life. New York: Basic Books

Heckman, J. J. (2013). Giving kids a fair chance. Cambridge, MA: MIT Press.

Hetherington, M. E., \& Parke, R. D. (2003). Child psychology: A contemporary viewpoint (5th ed.). New York: McGraw-Hill.

Hirsh-Pasek, K., Golinkoff, R.M., Ever, D.E. (2003). Einstein never used flashcards: How our children really learn and why they need to play more and memorize less. Emmaus, PA: Rodale Press.

Lamb, M. E., Thompson, R. A., Gardner, W., \& Charnov, E. L. (1985). Infant-mother attachment: The origins and developmental significance of individual differences in strange situation behavior. Hillsdale, NJ: Lawrence Erlbaum.

McDade, T. W., Ryan, C., Jones, M. J., MacIsaac, J. L., Morin, A. M., Meyer, J. M., ... Kuzawa, C. W. (2017). Social and physical environments early in development predict DNA methylation of inflammatory genes in young adulthood. Proceedings of the National Academy of Sciences of the United States of America, 114(29), 7611-7616. https://doi.org/10.1073/pnas.1620661114

Ministry of Education, Culture, Sports, Science, and Technology (2017). Course of study for Kindergarten. http://www.mext.go.jp/component/a_menu/education/micro_detail/_icsFiles/afieldfile/2017/05/12/138466 1_3_2.pdf.

Moore, S. R., McEwen L. M., Quirt, J., Morin, A., Mah, S. M., Barr, R. G., ...Kobor, M.S. (2017). Epigenetic correlates of neonatal contact in humans. Development and Psychopathology, 29, 1517-1538. https://doi.org/10.1017/S0954579417001213

National Research Council and Institute of Medicine [NRCIM] (2000). From Neurons to Neighborhoods: The Science of Early Childhood Development. Washington, DC: National Academy Press.

Nettle, D. (2008). Why do some dads get more involved than others? Evidence from a large British cohort. Evolution and Human Behavior, 29, 416-423. https://doi.org/10.1016/j.evolhumbehav.2008.06.002 
OECD, (2015). Skills for Social Progress: The Power of Social and Emotional Skills. OECD Skills Studies, OECD Publishing. https://doi.org/10.1787/9789264226159-en

Piaget, J., \& Inhelder, B. A. (1974). The child's conception of quantities. London: Routledge \& Kegan Paul.

Rutter, M. (2006). Genes and behavior: Nature-nurture interplay explained. London: Blackwell.

Siegler, R. S. (1986). Children's thinking. Englewood Cliffs, N.J: Prentice-Hall.

Singer, D., Golinkoff, R. M., \& Hirsh-Pasek, K. (Eds.) (2006). Play=Learning: How play motivates and enhances children's cognitive and social-emotional growth. New York, NY: Oxford University Press. https://doi.org/10.1093/acprof:oso/9780195304381.001.0001

Spector, T. (2012). Identically different: Why you can change your genes. London: Weidenfeld \& Nicolson.

Verny, T., \& Weintraub, P. (2002). Pre-Parenting: Nurturing Your Child from Conception. New York: Simon \& Schuster.

Watanabe, N. (2016). A basic study of a Math Play Learning Program for 3, 4\&5 year olds (1). Japan Journal of Mathematics Education and Related Fields, 57(3-4), 141-157.

Watanabe, N. (2017a). Accelerated cognitive development-Piaget's conservation concept. Journal of Educational and Developmental Psychology, 7(2), 68-74. https://doi.org/10.5539/jedp.v7n2p68

Watanabe, N. (2017b). Acquiring Piaget's conservation concept of numbers, lengths, and liquids as ordinary play. Journal of Educational and Developmental Psychology, 7(1), 2017. https://doi.org/10.5539/jedp.v7n1p210

Watanabe, N. (2019). Effective simple mathematics play at home in early childhood: Promoting both non-cognitive and cognitive skills in early childhood. International Electronic Journal of Mathematics Education, 14(2), 401-417. https://doi.org/10.29333/iejme/5739

Weaver, I. C. G., Cervoni, N., Champagne, F. A., D'Alessio, A. C., Sharma, S., Seckl, J. R., ... Meaney, M. J. (2004). Epigenetic programming by maternal behavior. Nature Neuroscience, 7, 847-854. https://doi.org/10.1038/nn1276

Weisberg, D. S., Hirsh-Pasek, K., Golinkoff, R. M., Kittredge, A.K., Klahr, D. (2016). Guided play: Principles and practices. Current Directions of Psychological Science. 25(3), 177-182. https://doi.org/10.1177/0963721416645512

Yin, R. K. (2018). Case study research and applications design and methods (6th ed.). Thousand Oaks, CA: Sage.

\section{Copyrights}

Copyright for this article is retained by the author(s), with first publication rights granted to the journal.

This is an open-access article distributed under the terms and conditions of the Creative Commons Attribution license (http://creativecommons.org/licenses/by/4.0/). 